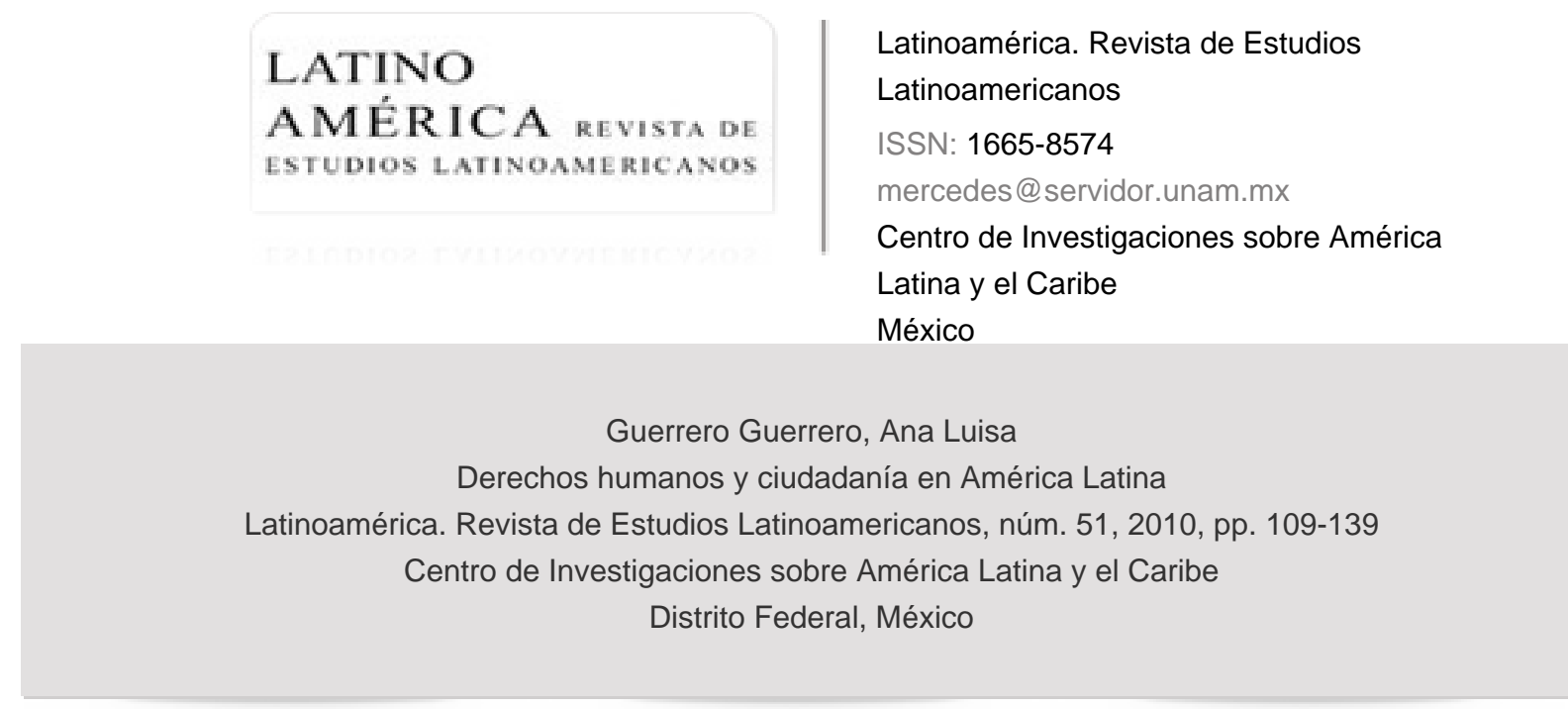

Disponible en: http://www.redalyc.org/articulo.oa?id=64015153006

- Cómo citar el artículo

- Número completo

- Más información del artículo

- Página de la revista en redalyc.org

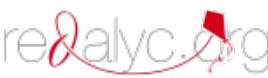

Sistema de Información Científica

Red de Revistas Científicas de América Latina, el Caribe, España y Portugal Proyecto académico sin fines de lucro, desarrollado bajo la iniciativa de acceso abierto 


\title{
Derechos humanos y ciudadanía en América Latina
}

\author{
Ana Luisa Guerrero Guerrero*
}

RESUMEN: En este trabajo se analizan las relaciones entre ciudadanía y derechos humanos en América Latina frente a la era global, desde una perspectiva filosófico-política. La adquisición de los diversos tipos de derechos humanos en América Latina se ha realizado de forma diferente, y con otro orden de aparición que el seguido en la región noroccidental de Norteamérica. Esta situación invita a reflexionar el significado y el sentido que tienen los derechos humanos en Latinoamérica, en la que la presencia de comunidades y minorías étnicas han demandado su derecho a tener derechos humanos, sin olvidar sus condiciones de diversidad cultural y asimetría respecto a la cultura occidental, que ha planteado un paradigma de los derechos humanos que los ha excluido por no asimilarse 0 convertir a sus miembros en individuos-ciudadanos occidentales.

Palabras Clave: Derechos humanos, Globalización, Ciudadanía, Paradigma occidental.

ABSTRACT: In this paper the relationship between citizenship and human rights in Latin American countries in this time of globalization is analyzed from a philosophical-political perspective. The adoption of varying types of human rights in Latin American countries has not evolved the same nor in the same order as in North America. This invites one to reflex on the meaning and significance this has on human rights in Latin America, most notably with certain communities and ethnic minorities that have demanded their human rights where their unique cultural diversity defines them in relation to a Western paradigm of human rights which has excluded them.

KEY wordS: Human rights, Globalization, Citizenship, Western paradigm.

"Centro de Investigaciones sobre América Latina y el Caribe, unam (anagro@correo.unam.mx). 


\section{PANorama General}

- Qué sentido pueden cobrar hoy los derechos humanos y la ciudadanía en un mundo globalizado ${ }^{1}$ en el que, no obstante, no existen Estado ni ciudadanía global? ¿Qué derechos humanos son más apremiantes o qué generación de $\checkmark$ derechos es la prioritaria? ¿Qué tipo de sociedad y formas de vida son afines a cada una de las generaciones de derechos humanos? ¿El concepto de ciudadanía agota el de los derechos humanos? Son preocupaciones que apuntan a tener presente, que la defensa total o parcial de los derechos humanos implica tomar partido, pues no es lo mismo entenderlos divididos que interdependientes.

Desde la perspectiva filosófico-política planteo el análisis sobre las justificaciones y alcances de las generaciones de los derechos humanos, que se han asumido en la cultura política occidental como la mejor vía en la defensa de la dignidad de todos los humanos. Así, utilizo tres documentos clave: la Encuesta, la cual fue preparada por la unESCO en 1947 y cuyas respuestas sirvieron de base y fondo a los redactores del segundo documento, y la Declaración Universal de los Derechos Humanos aprobada por la onv el 10 de diciembre de 1948. Además, como tercer documento, considero el Programa de las Naciones Unidas para el Desarrollo (2004): La democracia en América Latina (PNUD). ${ }^{2}$

1 "El desarrollo de las relaciones económicas, políticas, sociales y culturales ha adquirido en las últimas décadas una dimensión que se eleva por encima de las fronteras entre los estados e ignora las divisiones administrativas y políticas que se han establecido entre los pueblos. Transportadas por los medios de comunicación, por las nuevas tecnologías de la información, por las redes económicas y los flujos de personas, las acciones y decisiones de cada uno, por remotas que sean, pueden llegar a afectar la vida y el destino de poblaciones lejanas en cualquier lugar de la geografía del planeta. Para expresar esa nueva realidad utilizamos genéricamente el término globalización". Jurgen Habermas, David Held y Will Kymlicka, "Declaración de Granada sobre la globalización", en El País, 7 de junio, 2005.

2 Jacques Maritain, Los derechos del hombre, Barcelona, LAIA-UnESCO, 1976; La democracia en América Latina. Hacia una democracia de ciudadanos y ciudadanas. Contribuciones para el debate, Programa de la Naciones Unidas para el Desarrollo, PNud, Buenos Aires, Aguilar/Altea/Taurus/Alfaguara, 2004. Parte I y Parte II; Ideas y aportes: la democracia en América Latina, Colombia, Panamericana Formas e Impresos, 2004; La democracia en América Latina. Hacia una democracia de ciudadanos y ciudadanas. El debate conceptual sobre la democracia, PNud, Perú, Aguilar/Altea/Taurus/Alfaguara, 2004. 
Tales documentos los reviso a través de los conceptos de derechos humanos y ciudadanía, delimitándolos a un entorno y a una adscripción circunstancial contemporánea y regional latinoamericana. La relación entre ambos conceptos la establezco a través de otro, el de "sujeto" o "agente" de los derechos humanos, puesto que en la tradición occidental se ha asumido que el ciudadano es el sujeto de los derechos humanos, o bien, que la condición de ciudadanía es el elemento obligatorio para tener derechos humanos.

Tengamos presente grosso modo las generaciones de derechos humanos a las que en este escrito hago alusión. La primera generación está conformada por los derechos individuales, civiles y políticos, provenientes de las luchas burguesas; la segunda generación por los derechos económicos, sociales y culturales, efecto de las revoluciones socialistas; la tercera generación ${ }^{3}$ referida a los derechos de la diferencia cultural, de la paz y del desarrollo, también llamados derechos a la diferencia cultural y de solidaridad, ${ }^{4}$ provenientes de las constantes demandas de las minorías nacionales y grupos étnicos.

En la tradición iusfilosófico-política destacan dos formas de fundamentar los derechos humanos y tienen que ver con la manera de apreciarlos y valorarlos. La primera es el iuspositivismo, su principal característica es la idea de que los derechos humanos son derechos si y sólo si están positivados o reconocidos jurídicamente y apoyados en la fuerza del Estado, pues éste es el garante de su respeto y aplicación. La manera más radical de apelar al iuspositivismo es la que en el siglo xx sirvió para la instauración, legalización y legitimación de gobiernos totalitarios, fincados en la idea de que el único derecho es el positivo, y que aplicado por la autoridad se convierte en el último dictaminador o "dictador" de la justicia.

${ }^{3}$ Esta perspectiva puede ilustrarse con las siguientes obras: Eduardo Pablo Jiménez, Los derechos bumanos de la tercera generación, Buenos Aires, EDIAR, 1997; Karel Vasak, Las dimensiones internacionales de los derechos humanos, Barcelona, Editor General Serbal/ unESCO, vol. II, 1984; A. Pérez Luño, La tercera generación de derechos humanos, Navarra, Aranzadi, 2006.

4 "La Carta Africana incorpora esta nueva generación de derechos del hombre con el nombre de derechos de solidaridad de los pueblos y éste es el principal beneficio. El hecho que también sobresale es que es la primera vez que un instrumento internacional, su artículo 20, consagra expresamente, el derecho de los pueblos a la existencia". Philippe Richard, Droits de l'bomme, droits des peoples, Lyon, Chronique Sociale, 1995, p. 46. 
Como contraparte de esta postura se encuentra otro nivel de reflexión: el iusnaturalista, que sostiene que la validez del derecho va más allá de la positivación de los códigos de normas y costumbres; el criterio para el derecho no descansa en el cumplimiento y aplicación de las reglas prescritas por el derecho positivo, se encuentra fuera de él, es decir, en la ley natural que es superior y guía reguladora de sus modificaciones y adaptaciones.

Sin embargo, el iusnaturalismo puede ser empleado tanto para impugnar el derecho positivo como para justificarlo, ejemplo de esto último se da siempre que se arguya que un determinado derecho positivo es correcto porque positivó el "modelo", que se ajusta a los lineamientos de la ley y el derecho naturales. En consecuencia, si el derecho positivo excluye a ciertos sujetos como agentes jurídicos no sólo es legal, sino legítimo, pues acudió a una ley superior que dirigió su estructuración, contenido y aprobación. Esta forma de pensar, puede ser ilustrada de varias maneras, una de ellas es la que Locke plasmó en "The Fundamental Constitutions of Carolina", donde manifiesta que el hombre digno, el propietario y creyente (cristiano), ${ }^{5}$ debe ser el sujeto de las convocatorias políticas, puesto que es quien tiene derechos naturales a tener derechos políicos. ${ }^{6}$ Desde estas épocas ya había lugar a solicitarle a la autoridad que fungiese como guardiana de las esferas consideradas básicas del individuo, y la más demandante fue el derecho a

5 John Locke, "The Fundamental Constitutions of Carolina", en Political Writings, Londres, Penguin Books, p. 210. Este autor entiende por creyente al hombre cristiano, el ateo no es digno de confianza y, por ende, tampoco de reconocimiento político.

${ }^{6}$ No hay lugar para el desarrollo de los fundamentos a los que apela cada corriente de derechos, ni para abundar en los diversos autores y perspectivas al interior de cada una de ellas, ya que no son escuelas monolíticas, por ejemplo, en el iusnaturalismo hay que distinguir entre ius naturae y ius naturale. Además, entre los fundamentos que se ofrecen se encuentran diferencias significativas, no es lo mismo decir que el origen del derecho se encuentra en la naturaleza, que en Dios o en la naturaleza humana o en la naturaleza racional del hombre. Respecto al iuspositivismo se requiere matizar conceptos como los siguientes: formalismo jurídico, justicia, el derecho como forma y la teoría formal del derecho. Para profundizar estos temas se recomiendan las obras siguientes: Eduardo García Máynez, Positivismo jurídico, realismo sociológico y iusnaturalismo, México, Fontamara, 1993; H. Kelsen y N. Bobbio y otros, Crítica del derecho natural, Madrid, Taurus, 1996; C. I. Massini-Correas [comp.], El iusnaturalismo actual, Buenos Aires, Abeledo-Perrot, 1996. 
la propiedad. Éstas son las simientes de las ideas sobre el Estado mínimo, cuya función principal es aplicar la fuerza y el orden con base en las necesidades naturales de los individuos, interpretadas como igualdad para la libertad.

Los intentos de fundamentaciones totales y absolutas de los derechos humanos pueden llegar a caer en fundamentalismos, en posturas extremistas que excluyan formas de vida, maneras de sentir y valorar lo correcto, y que en lugar de argumentar las bases éticas de los derechos humanos logren, en cambio, servirse de ellos para justificar o negar dogmáticamente costumbres, culturas o elecciones individuales en su dimensión política y civil de forma radical. Aspecto este último que puede ser muy costoso para grandes poblaciones e individuos en el mundo contemporáneo, que permanecen en penumbra o fuera de los agentes de los derechos humanos al serles negados sus derechos a sus formas de ser y costumbres. Por otro lado, actualmente las pretensiones de fundamentaciones totales y absolutas de los derechos humanos han caído en descrédito por haber conducido a confrontaciones estériles, lo que ha propiciado la tendencia a poner en contexto los derechos humanos, abriendo paso así a teorías menos fundacionistas, lo cual pretendo realizar, pero no por ello carentes de perspectiva y argumentaciones.

Desde este enfoque planteo las contribuciones que T. H. Marshall vertió en su obra Ciudadanía y clase social, publicada en 1950, ya que sus agudas reflexiones sobre tales conceptos lograron una perspectiva de los derechos humanos más allá de fundacionismos radicales entre iuspositivistas y iusnaturalistas, propuso un modelo de explicación procesual de los derechos humanos. ${ }^{7}$ Marshall estableció relación entre las distintas etapas de la ciudadanía: la civil, la política y la social, con el advenimiento de las luchas que estuvieron detrás de las adquisiciones de los derechos humanos en sus vertientes individual y social.

La obra del sociólogo inglés ha sido objeto de crítica y nuevas investigaciones en Europa, situación que no ha sucedido en Latinoamérica, lo que hace ne-

${ }^{7}$ Postura que es criticada aquí en tanto suele ser utilizada para interpretar la aparición de los derechos humanos en la historia europea, como el paradigma frente al que los desarrollos de los derechos humanos en otras regiones deben coincidir para ser legítimos, como ya apuntaremos en su momento. 
cesaria una revisión crítica de sus alcances y limitaciones para la comprensión de esta región del continente americano, a la que su obra no considera, pero a la que se le ha impuesto, a la hora de explicarla, el modelo de desarrollo de los derechos humanos y de la ciudadanía propuesta por este autor.

Finalmente, enmarco estas preocupaciones en la condición actual contemporánea llamada la era global, que integra elementos específicos en las vinculaciones y diferencias entre América Latina y el resto del mundo. Ya que en este proceso de globalización los efectos "positivos" del mercado global no se distribuyen del mismo modo, sobre todo en sentido económico, este aspecto permanece en las zonas geográficas de los países ricos y postindustrializados. El clima intelectual e histórico que rodea la situación contemporánea está perfilado por la desilusión y pérdida de los grandes proyectos, de las grandes narraciones acerca del progreso de la humanidad y la desarticulación de movimientos reivindicatorios respecto a propuestas teórico-políticas. Lo que de algún modo ha servido para que las naciones poderosas se autoarroguen el derecho de representar sus propios beneficios en nombre de la salvación de la civilización, ya sea de forma "pacífica" administrándolos a su favor o, en el peor de los casos, a través de guerras que defiendan su seguridad nacional. A pesar de ello, la tesis que mantengo a lo largo de este texto es que los derechos humanos declarados por la onu se mantienen todavía como la mejor apelación para la protección a la integridad de los seres humanos, puesto que son principios generales en defensa de los individuos y colectividades contra los abusos, la violencia y la tiranía de los poderes políticos. Asimismo, esbozo la propuesta de no sumisión de los derechos humanos a la ciudadanía, en el sentido de que los derechos humanos tienen mayor alcance y capacidad para establecer relaciones de respeto que las exclusivamente políticas. A los derechos humanos los considero como conceptos ético-políticos y al de ciudadanía como político. 


\section{Primera y Segunda Generaciones de DeReChos humanos en AmÉrica Latina}

En el verano de 1947 la unesCO ${ }^{8}$ consultó a destacadas personalidades por medio de una Encuesta acerca del significado de los derechos del hombre. Las respuestas así obtenidas sobre un mismo tema constituyeron, ellas mismas, un acontecimiento previo a la aprobación de la Declaración Universal de los Derechos Humanos por la Asamblea General de la Organización de las Naciones Unidas el 10 de diciembre de 1948. En la presentación de sus resultados, Jacques Maritain afirmó que existía diversidad de opiniones debido a las distintas valoraciones morales de los entrevistados, ya que en sus respuestas siempre se reflejaba un trasfondo cultural que revelaba las causas de las diferentes opiniones.

La Encuesta, que se caracterizó por contener reflexiones detenidas, puso en alerta a los redactores de la nueva Declaración, para no permanecer en la cuestión de los fundamentos filosóficos o las implicaciones de la defensa de ciertas formas de vida congruentes con ciertos derechos. Aspecto que se logró con el costo de no hacer evidente la necesidad de recurrir a las reflexiones éticas para afianzar el carácter diverso de los derechos humanos. De esta forma, la Encuesta tuvo la función de ser el sedimento intelectual para la apremiante demanda de una nueva Declaración, cuyo objetivo fue más bien pragmático que reflexivo.

8 "La preparación de una declaración de derechos del hombre se enfrenta a problemas fundamentales que conciernen tanto a los principios y las interpretaciones, como a otros problemas de índole política y diplomática relacionados con los acuerdos y la redacción. Por esta razón ha emprendido la Comisión sobre Principios Filosóficos de los Derechos del Hombre de la unEsco, basándose en un estudio de la opinión de los expertos de diferentes partes del mundo, un examen de las bases intelectuales de una declaración moderna de derechos, esperando que ese estudio pueda ser útil a la Comisión sobre derechos del Hombre del Consejo Económico y Social tanto para sugerir bases comunes de acuerdo, como para explicar el origen de las posibles diferencias. La Comisión de la unEsco está convencida que los miembros de las Naciones Unidas comparten convicciones comunes de las cuales dependen los derechos humanos, pero está también convencida de que esas convicciones comunes están expuestas en función de diferentes principios filosóficos y sobre un fondo de sistemas políticos y económicos divergentes." Los derechos del bombre, p. 390. Solamente menciono a algunas de las personalidades participantes: Mahatma Gandhi, E. H. Carr, Jacques Maritain, Harold Laski, Benedetto Croce, Aldous Huxley. 
La Comisión de la onu que se ocupó de tal tarea empleó una metodología9 que condujo a acuerdos generales sin adentrarse en fundamentaciones de carácter teórico, evitándose con ello la posible radicalización de puntos de vista que obstaculizara la adhesión y, posterior, aprobación de una Declaración Universal por países con culturas distintas. ${ }^{10}$

La Declaración de Derechos de 1948 revela las dos generaciones de derechos humanos que, como se expresa en la publicación de la Encuesta,

son en cierto modo complementarias y en cierto modo opuestas [...]. Una surgió de la premisa de los derechos individuales innatos y de un prejuicio contra una autoridad central poderosa y contra la intervención del gobierno, mientras que la otra se basaba en principios marxistas y en la premisa de un gobierno central poderoso y pronto se unió a una planificación total (que automáticamente aumentó el poder central) y al gobierno de un solo partido (que inevitablemente redujo algunas libertades políticas). ${ }^{11}$

De la Encuesta destaco aquí sólo algunas de sus cuestiones con el objeto de desenterrar de la memoria de la teoría de los derechos humanos los pensamientos que acapararon la atención del mundo en ese momento y, con ello, mostrar que su vigencia consiste en el debate acerca de las causas que expliquen por qué no se han resuelto todavía y de la compatibilidad o incompatibilidad de sus generaciones. Algunos autores insisten en que las distintas generaciones de derechos humanos son antagónicas solamente a la letra y que del mismo modo pueden ser armónicas, es decir, declararlas compatibles. Otros afirman que los diferentes tipos de derechos humanos son derechos irreconciliables de forma real

9 El ejercicio político condujo a la aprobación de esta nueva Declaración.

${ }^{10}$ Las líneas de preocupación contenidas en la Encuesta no pudieron ser formuladas de forma cerrada, por ende, las respuestas tampoco podían haber sido meramente descriptivas, ya que manifestaron las diferencias en cultura y procedencia de quienes las respondieron que rebasa un único enmarque cultural. En todos los encuestados hubo conciencia del clima político de posguerra: la esperanza y el desencanto, la necesidad de poner diques tanto a la capacidad de exterminio como a la intolerancia y al poder desenfrenado. La Encuesta se convirtió en la conciencia, en el imperativo para defender a todos los hombres y a las mujeres de los atentados a su dignidad, pese a las enormes diferencias y formas de justificarla.

${ }^{11}$ Jacques Maritain, Los derechos del hombre, Buenos Aires, La Pléyade, 1972, p. 383. 
y efectiva. Pero veamos, apreciemos los cuestionamientos de la Encuesta que ensamblan las tradiciones de los derechos humanos, ahí se manifiestan distintos tipos de derechos: los políticos y los sociales:

1. ¿Cuáles son las relaciones entre los derechos políticos, sociales y económicos de los individuos (de sexo y edad diferentes) y de los grupos, en sociedad de tipos diferentes y en circunstancias históricas distintas? 2. Las diferencias entre declaraciones divergentes de derechos y libertades humanos ideales, en diferentes sociedades, ihasta qué punto son indicios exactos de las diferencias materiales de las condiciones económicas y sociales de las regiones en cuestión? 3. ¿Hasta qué grado se han alterado las relaciones personales y de grupo (por ejemplo, de clase, nacionales e internacionales) en las principales regiones avanzadas del mundo, durante los últimos cien años? [...]. 4. ¿Hasta qué grado han sido modificados los derechos de los individuos y de los grupos, en la teoría y en la práctica, por los acontecimientos acaecidos desde entonces? 5 . ¿Cuáles son las relaciones entre derechos y los deberes a) para los individuos, y b) para los grupos? ¿Y cuáles las relaciones entre las libertades individuales y las responsabilidades sociales o colectivas? 6. ¿Qué situaciones de necesidad justifican la restricción o la supresión de los derechos y libertad normales? ${ }^{12}$

Estas preguntas brindan la oportunidad de abordar la obra de T. H. Marshall, Ciudadanía y clase social, ${ }^{13}$ ya que inauguró un área de estudio correspondiente a la relación entre ciudadanía y derechos humanos. ${ }^{14}$

T. H. Marshall entendió ese proceso como la reunión de factores que propiciaron los derechos civiles, políticos y económicos, al que se ha llamado "el desarrollo de la ciudadanía sustantiva, que es el cuerpo creciente de derechos civiles, políticos y sociales". ${ }^{15}$ Su perspectiva se orientó a presentar la evolución de los derechos humanos en correspondencia con los distintos tipos de ciuda-

${ }^{12} \mathrm{Ibid}$., pp. 385 y 386.

${ }^{13}$ Madrid, Alianza Editorial, 1998.

${ }^{14}$ Steven Lukes y Soledad García opinan que esta obra es una contribución al esclarecimiento de la trayectoria de los derechos humanos en Europa y, en especial, en Inglaterra, al interpretar la ciudadanía como un proceso que está integrado en el de los derechos humanos. Soledad García y Steven Lukes [comps.], Ciudadanía: justicia social, identidady participación, Madrid, Siglo xXI, 1999, p. 3 .

${ }^{15}$ Marshall, op. cit., p. 111. 
danía, es decir, como procesos complementarios y progresivos. Aunque, también, los percibió como relaciones problemáticas, en el sentido que no está asegurada su conciliación de forma indefinida. Lo dijo así: "Pero la tendencia actual hacia la igualdad social es, a mi parecer, la última fase de una evolución de la ciudadanía que ha conocido un progreso ininterrumpido desde hace doscientos cincuenta años" y, al final de la obra, afirma:

Esta fase no se prolongará indefinidamente. Puede que los conflictos dentro de nuestro sistema social plantee en tales contradicciones que el compromiso logre sus propósitos durante mucho tiempo más [...]. Mi objetivo ha sido esclarecer en la medida de lo posible un elemento cuya importancia juzgo fundamental, esto es, la influencia de un concepto que se desarrolló con enorme rapidez, cual es el de los derechos humanos, en la estructura de la desigualdad social. ${ }^{16}$

El entorno de los derechos humanos y la ciudadanía que ocupó a Marshall no tuvo por objeto mostrar los dilemas que en otros ámbitos geográficos e históricos pudieran presentarse, sino sólo el que prevaleció en Inglaterra, dio por sentado en su análisis dos aspectos relevantes. El primero, que era un modelo de explicación que si era válido para Inglaterra lo podía ser para Europa. El segundo, el autor nunca cuestionó si la relación entre ciudadanía y derechos humanos fuese una adquisición completa y exhaustiva. Respecto a este punto, Giovanna Procacci menciona: "Su centro focal era una sociedad que se consideraba poseedora de una cultura común no problemática", ${ }^{17}$ lo que significa que no tenía en mente una confrontación con otras bases culturales que no fueran las de Occidente. Marshall sancionó el giro socialdemócrata inglés hacia el Estado de bienestar, al atribuir a los derechos sociales la misma legitimidad teórica que tienen los civiles y políticos.

Marshall consideró la evolución de los derechos humanos desde una concepción específica de la historia occidental, propuso a la ciudadanía sustantiva como la integración de las diversas etapas de los derechos humanos, mejor

\footnotetext{
${ }^{16} \mathrm{Ibid}$., pp. 22 y 82.

${ }^{17}$ Véase Giovanna Procacci, "Ciudadanos pobres, la ciudadanía social y la crisis de los estados del bienestar", en García y Lukes, op. cit., p. 8.
} 
dicho, como una progresión de etapas de la ciudadanía a las que el Estado se compromete implementar por medio de políticas sociales.

El elemento civil (de la ciudadanía) se compone de los derechos necesarios para la libertad individual: libertad de la persona, de expresión, de pensamiento y religión, derecho a la propiedad y establecer contratos válidos y derecho a la justicia [...]. Por elemento político entiendo el derecho a participar en el ejercicio del poder político como miembro de un cuerpo investido de autoridad políica, o como elector de sus miembros. El elemento social abarca todo el espectro, desde el derecho a la seguridad y a un mínimo de bienestar económico, al de compartir plenamente la herencia social y vivir la vida de un ser civilizado conforme a los estándares predominantes en la sociedad [ ... ]. Podemos asignar el periodo formativo de cada uno a un siglo distinto -los derechos civiles, al siglo xvII; los políticos al xix; y los sociales al xx..$^{18}$

El fait reconocido en la obra de Marshall es el crédito que tienen ambos tipos de derechos a través del concepto de ciudadanía con el respaldo del $E s$ tado. No hay en esta obra una propuesta de dislocar unos derechos a favor de otros. Definió a la ciudadanía así:

es aquel estatus que se concede a sus miembros de pleno derecho de su comunidad y sus aspiraciones de igualdad de derechos tuvo como contraparte el sistema de desigualdad que implicaba el desarrollo del capitalismo. [Por ejemplo] [... en el siglo xix la ciudadanía en forma de derechos civiles era universal, el sufragio político no formaba parte de los derechos de ciudadanía, puesto que era privilegio de una reducida clase económica. ${ }^{19}$

La percepción de Marshall es emblemática de la defensa de los derechos sociales como una intervención del Estado,

La obligación del Estado es para con toda la sociedad, cuyos problemas se reparan en el parlamento o en un consejo municipal, y no para los ciudadanos individua-

${ }^{18}$ Marshall, op. cit., pp. 22-23 y 26. Los derechos civiles y políticos son llamados de la primera generación de derechos; los sociales y económicos de la segunda generación. Los derechos de la tercera son los que persiguen la identidad cultural y la autodeterminación de los pueblos.

${ }^{19}$ Ibid., pp. 10, 35 y 38 
les, cuyas reparaciones están adscritas a un tribunal de justicia, o al menos en un casi tribunal de justicia. La conservación de un equilibrio apropiado entre esos elementos colectivos e individuales de los derechos humanos es un asunto vital para el Estado democrático socialista. ${ }^{20}$

Su contraparte es reconocida por la corriente neoliberal que ha logrado en la actualidad desmantelar el compromiso de algunos estados con el abatimiento de las desigualdades, primero con las de clase social y, posteriormente, con el reconocimiento de otras desigualdades, como las de los pueblos indios que pugnan por sus derechos a pervivir y al desarrollo. Así provienen las críticas a la presencia de los derechos sociales, económicos y culturales como no auténticos, como carentes de sujeto o de agente apropiado para su ejercicio y demanda jurídica. Se convierten en uno de los centros de ataque de los opositores a que el Estado tenga obligaciones en la creación de proyectos sociales y políticos que protejan a los menos favorecidos, ${ }^{21}$ como lo señala Giovanna Procacci:

Los derechos sociales son incompatibles por naturaleza con los derechos subjetivos universales: no piden más libertad frente al poder del Estado para garantizar servicios. No hay pues ninguna progresión de los derechos civiles y políticos a los sociales, hay algo más que una discontinuidad, hay una verdadera ruptura dentro de los derechos $[\ldots]$. Los derechos sociales resultan problemáticos desde el punto de vista jurídico por su escaso nivel de definición procesal, y en consecuencia de uniformidad, y por el elevado nivel de gasto económico que suelen exigir. ${ }^{22}$

Los neoliberales, opositores de Marshall, pretenden superar las cargas ideológicas de las generaciones de derechos humanos y desactivar su peso moral y político, a través de la idea de que los derechos de la primera generación son jurídicamente fuertes y los únicos, auténticos y exclusivos derechos universales.

${ }^{20} \mathrm{Ibid}$., p. 62.

${ }^{21}$ De la gama de autores que niegan a los derechos sociales y económicos el estatus de derechos humanos destacan, en el ámbito de la diplomacia y la política, Jean Jordan Kirkpatrick (19262006), funcionaria del gobierno de Reagan, se puede consultar The Withering Away of The Totalitarian State (1992), en el de la filosofía política, Robert Nozick (1938-2002) Anarchy, State and Utopia, y en el de la economía, F. A. Hayek (1899-1992) The Road to Serfdom.

${ }^{22}$ García y Lukes, op. cit., p. 25. 
Por ello, las propuestas neoliberales sostienen que los derechos humanos tienen asignado un sujeto facultado para ejercerlos jurídicamente, y que éste es además depositario de la dignidad humana, al asumir que este concepto jurídico es compatible con todas las formas de derechos humanos, y de este modo no se tiene que apelar a la clase social, sino al individuo pobre o rico, proletario o burgués. De igual modo, no se considera al colectivo o minorías, sino al individuo indio, se asegura así que la única vía de entrada a los derechos humanos sea siempre el individuo. ${ }^{23}$

Consideremos qué se entiende por agencia:

La noción de agencia tiene implicaciones directas y concurrentes en las esferas civil, social y política, debido a que es una concepción moral, en muchos aspectos legalmente sancionada, del ser humano como un individuo autónomo, razonable y responsable [...]. Esta visión de la agencia no sólo ha sido adoptada por algunos países ricos; es una visión que también ha sido inscrita en la conciencia moral de la humanidad por la Declaración Francesa de Derechos del Hombre y del Ciudadano, por el Prólogo y la Primera Enmienda de la constitución de los Estados Unidos, y, más tarde, por la Declaración Universal de los Derechos Humanos de las Naciones Unidas, el Acuerdo Internacional sobre Derechos Civiles y Políticos, el Acuerdo Internacional sobre Derechos Económicos, Sociales y Culturales, la Declaración de Derechos de Viena, la Convención Americana sobre Derechos Humanos. ${ }^{24}$

La agencia concebida como el sujeto racional-autónomo corresponde al individuo posesivo del liberalismo, y que ha dado base a la noción de que los derechos individuales son considerados universales y en ellos se incluyen los derechos a la igualdad y a la libertad. Sin embargo, estos derechos no tienen como finalidad organizar a la sociedad como una unidad, ya que los derechos a la igualdad y a la libertad son derechos para el individuo no para la unidad social o el bien común, con ellos se preservó la desigualdad efectiva y se justificó la formalidad jurídica de la igualdad de todos los hombres ante la ley. ${ }^{25}$

${ }^{23}$ Las corrientes conservadoras o neoliberales basan, específicamente, su rechazo a los derechos sociales y económicos como derechos humanos sobre estas características.

${ }^{24}$ La democracia en América Latina..., p. 36.

25 "El individuo es, en esencia, sacrosanto y es libre e igual sólo en la medida en que puede perseguir e intentar realizar los fines y los intereses personales escogidos por él [...]. De acuerdo 
Los teóricos de los derechos humanos, que encubren las finalidades de las tradiciones de derechos, sostienen que las diferencias entre ellos sólo son de matices, así la tarea para hacer que coincidan es teórica. Los derechos humanos logran adquirir el carácter de indivisibilidad si se les ajusta a la letra.

Jack Donnelly ilustra esta postura, piensa que ambos tipos de derechos humanos son compatibles si no se evidencian sus orígenes ideológico-políticos, pues de otro modo se contribuye a su alejamiento, al segregar a unos en nombre de otros. Opina que si se llega a superar esta oposición, entonces, todos los derechos deben ser vistos como básicos y mutuamente interdependientes. Afirma que hay que defender que todos los derechos humanos son básicos o, de otro modo, se da la posibilidad de apoyar la suspensión o desaparición de un tipo de derechos en detrimento de otros. ${ }^{26}$ Este especialista ${ }^{27}$ tiene claro que un gran número de conservadores y liberales han argumentado en contra de los derechos sociales y económicos, aduciendo que realmente no son derechos humanos por-

con esta perspectiva el Estado moderno debería proporcionar las condiciones necesarias para posibilitar a los ciudadanos la persecución de sus propios intereses [...]. Éste ha sido, desde Locke, un principio central del liberalismo: el Estado existe para salvaguardar los derechos y libertades de los ciudadanos que son, en último término, los mejores jueces de sus propios intereses; el Estado es la carga que tienen que soportar los individuos para garantizar sus propios fines; y el Estado debe estar restringido en cuanto a su ámbito [.. . . Por el contrario los pensadores de la Nueva Izquierda [... para tomarse en serio la igualdad y la libertad hay que cuestionar la visión de que los individuos dejados, en la práctica, a sus propios medios en una economía de mercado [... ] la igualdad, la libertad y la justicia -que ellos reconocen como los grandes ideales universales - no pueden alcanzarse en un mundo dominado por la propiedad privada y la economía capitalista." David Held, Modelos de democracia, México, Alianza Editorial, 1992, p. 323.

${ }^{26}$ No voy a desarrollar la noción de derechos básicos, estoy de acuerdo con señalar que son todo aquello que cada uno requiere para observar con respeto a cada uno de los otros, idea cercana a la de dignidad y a las características valiosas dentro de una cultura. Véase Jack Donnelly, Universal Human Rights in Theory and Practice, Ithaca, Nueva York, Cornell University Press, 1991, p. 40.

${ }^{27}$ Este autor elabora otra forma muy interesante de exponer la dicotomía entre derechos civiles y políticos y los sociales y económicos, que estructura así: (1) subsistence and personal rights, (2) legal rights, (3) civil, social and cultural rights, (4) economic rights y (5) political rights. La postura es moderada y a favor de la defensa de mostrar la interrelación entre todos los derechos humanos. Y que si bien no concuerdo con toda su exposición, reconozco que es una contribución al debate del tema. Ibid., pp. 35 y 36. 
que pertenecen a una categoría lógica diferente, refieren directamente una parte de la humanidad en particular, como es la clase social, y no a todos los seres humanos, a diferencia de los derechos políticos y civiles que son universales y que, por lo tanto, para que sean universales los derechos sociales habría que adjuntarlos a los individuales, o subsumirlos a ellos. Donnelly atiende algunas de las objeciones a las posturas de los conservadores, él mismo reconoce limitaciones en ellas. No obstante, su perspectiva no permite comprender por qué debemos esclarecer las grandes dificultades entre los diferentes tipos de derechos humanos, su planteamiento permanece en la idea de que al expresar que hay derechos humanos irreconciliables van a permanecer de ese modo, y nunca arriba en su estudio a la necesidad de explorar qué significa ética y políticamente que haya generaciones de derechos humanos.

El punto central es que el hecho de no evidenciar críticamente las profundas diferencias entre las generaciones de derechos humanos frente a la pérdida de paradigmas políticos, paraliza la creación de nuevas maneras de comprenderlos e interpretarlos frente a nuevas condiciones de opresión. El Estado mínimo no garantiza el cumplimiento de los derechos humanos económicos y sociales; y es que los derechos políticos y civiles, los derechos económicos y sociales (los derechos a la identidad, así como los de las generaciones por venir) no piden o quieren lo mismo. Por ejemplo, defender el derecho a aprender en la escuela la propia lengua, o el derecho a huelga, o el derecho de un individuo a emitir su voto en una casilla, no significan o persiguen una misma condición. Estas vertientes de derechos son distintas, puesto que se fincan en necesidades diversas con trasfondos políticos que no necesariamente son coincidentes.

Donnelly arguye que la pregunta: ¿quiénes son los sujetos de los derechos humanos? Tiene como respuesta los ciudadanos, y detrás de ellos, los individuos, sólo las personas individuales son seres humanos. Esta afirmación, que desde la perspectiva psicológica es cierta, debe ser puntualizada, ya que el peso filosófico y cultural que tiene es importante. En especial, el énfasis en el individuo puede conllevar al individualismo.

Los pensadores liberales tratan de entender la sociedad, el Estado y la economía como la suma de las acciones de los individuos. De hecho, han desarrollado una 
ideología intelectual profesional sistemática para su práctica, a la que se conoce como individualismo metodológico, método que insiste en que ésta es la única forma, no basada en la superstición, en la que es posible entender esas entidades: que literalmente no hay nada más que entender que la existencia de meros individuos. En su política, los liberales defienden con tenacidad los derechos individuales, y al menos en sus preferencias culturales manifiestas, valoran mucho el desarrollo de la individualidad, lo cuidan sobremanera. ${ }^{28}$

Por lo tanto, el individualismo en el sentido anterior puede dar sustento a la proclamación de que los derechos humanos son un bloque sagrado de principios universales y fundados en una ética individualista. Tesis que conduce a actitudes teórico-políticas que generalizan una situación humana, para esencializarla y proponerla como una condición universal de todos los humanos.

Por mi parte, no comparto la perspectiva de una teoría de los derechos humanos sin realidad circunstancial, pienso que las filosofías éticas sin moral, o en términos absolutos o, bien, la teoría políica sin contexto histórico son estériles elucubraciones para comprenderlas e interpretarlas, por ejemplo, se ven impedidas para observar que no todos los individuos o grupos comparten por igual las mismas cualidades de ciudadanía en el sentido más amplio; tampoco se puede acceder al hecho de que la ciudadanía no es adscrita a un gran sector de la humanidad, y que no por ello los derechos humanos le deben ser negados. En este sentido, ¿qué es lo básico, en qué consisten las necesidades fundamentales? ¿Se reducen a las necesidades básicas en sentido biológico o están ligadas a lo más preciado, lo digno, la mejor vida? Ambos sentidos de lo fundamental están comprendidos en ellos, pero, el individualismo metodológico es proclive a la adopción del relativismo ético como base de una sociedad democrática. ${ }^{29}$ John Dunn lo acota así:

${ }^{28}$ John Dunn, La agonía del pensamiento político occidental, Madrid, Organización Editorial de la Universidad de Cambridge, 1996, p. 53.

29 Declarar que los derechos humanos consisten en la defensa de los derechos básicos es una idea vacía, por tal razón, hay que acercar el contexto a la estructura de las interrogantes para dotarlas de contenido, es decir, para intentar responderlas. 
Si el relativismo ético es la filosofía según la cual las costumbres y valores de una tribu son tan buenos como los de otra -o quizá sería mejor decir que no tiene sentido preguntarse si las costumbres de una tribu son mejores que las de otra, dado que lo bueno y lo mejor son conceptos que obedecen a una definición intratribal-no tarda en aparecer el interrogante sobre qué tienen las tribus que las hace tan especiales ¿Y por qué no las naciones, los Estados, incluso los imperios (con su terrible fama)? Y si nos vamos al otro extremo, ¿por qué no las provincias, las ciudades, los pueblos, hasta las calles y las casas? [.. . ] ¿Por qué no hemos de aceptar también que las costumbres y los valores de un individuo son tan buenos como los de los de todos los demás [...]. Tal como viera Trasímaco con tanta claridad - o al menos tal como lo veía según Platón nos lo presenta- el relativismo ético, en política, va unido conceptualmente al nihilismo, y el nihilismo, en cuanto doctrina ética, hace imposible que un agente tenga una razón buena para negar a los demás lo que quiera que éstos deseen y puedan apropiarse. ${ }^{30}$

Los autores que apoyan la indiferenciación, entre las vertientes de derechos humanos, sostienen que los derechos económicos, sociales y culturales, los civiles y políticos son derechos de individuos, sin preocuparse por su dimensión social y cultural. Dichos autores afirman que los derechos a la alimentación, la salud, el trabajo, la seguridad social, libertad de prensa, protección contra la discriminación, etc., son derechos ejercidos por los individuos, éstos son los depositarios de los derechos humanos y no colectivos de ningún tipo como ya señalé antes. Pasan por alto, que si bien los individuos son miembros de comunidades, de las clases sociales, de los sindicatos, etc., los derechos sociales no son la versión agrandada, lineal y progresiva de los derechos políticos; no son derechos que se finquen en soluciones procedimentales para resolver tensiones entre la realización individual y sus condiciones sociales. Los derechos sociales y culturales son derechos diferentes de los individuales, para pretender articularlos es indispensable comprenderlos en su contenido.

Los derechos sociales y económicos tienen una nueva función comprometida con los grupos desfavorecidos desde la educación, la salud, la protección social; las demandas de los derechos sociales no son reglas formales. En consecuencia,

30 "El hombre racional es un psicópata que negocia los obstáculos que se oponen a sus deseos con una asertividad instrumental." Dunn, op. cit., p. 98. 
más que venir a completar los derechos humanos anteriores, representan rupturas puesto que evidencian que los derechos a la libertad liberal no son la respuesta para abatir la pobreza, ni para enfrentar la desigualdad social, ni tampoco para defender derechos colectivos como los derechos a la diferencia étnica y cultural. ${ }^{31}$

Se hace necesario pensar, entonces, que los propósitos de la indistinción de las cargas ideológicas y políticas de las generaciones de derechos tiene el propósito de mermar el apoyo a los derechos sociales y económicos, así como a los de la tercera generación. Además, con la consagración del agente ciudadano se canoniza la idea de que existe un contexto y un único sujeto, legítimo y ejemplar de los derechos humanos. Estos esfuerzos de carácter intelectual, moral, político y jurídico son parte del sustento del neoliberalismo. En consecuencia, desde esta perspectiva, los derechos sociales y económicos, así como los grupales y culturales serían seudoderechos, ${ }^{32}$ supeditados al cargo que se atribuya al individuo: el sujeto de los derechos humanos y naturales.

La Declaración de Derechos Humanos de 1948 reconoció la importancia de una y otra vertientes de derechos. Sin embargo, este suceso ha sido revertido

\footnotetext{
${ }^{31}$ En 1951, la Asamblea General de la onu inició la discusión acerca de la pertinencia de elaborar dos documentos por separado; uno sobre los derechos civiles y políticos y, otro, sobre los sociales y económicos. "Los partidarios de la preparación de dos Pactos alegaron que era posible exigir el cumplimiento de los derechos civiles y políticos mediante leyes y sanciones, pero que no se podía - o querría - hacer lo mismo con los derechos económicos, sociales y culturales; que el acatamiento de los primeros podría lograrse inmediatamente, mientras que el de los segundos tendría que realizarse de manera progresiva; y que, en términos generales, los primeros eran derechos del individuo 'contra' el Estado - es decir contra las disposiciones ilegales o injustas del Estado- mientras que los segundos eran derechos para cuya promoción el Estado tendría que tomar medidas positivas. Ya que la naturaleza de los derechos civiles y políticos y la de los otros derechos, así como las obligaciones respectivas del Estado, son diferentes, era preferible redactar dos instrumentos separados." Ambos documentos fueron adoptados como Pactos en 1966. Véase Elisabeth Reimann y Fernando Rivas Sánchez, Derechos Humanos: ficción y realidad, Madrid, Akal Editor, 1980, p. 339.

32 "El derecho de libre determinación ha sido un problema sumamente controvertido. Una escuela sostiene que es un 'principio político' muy importante, pero no un derecho jurídico en su sentido estricto, y que los vocablos 'pueblos' y 'naciones' no pueden ser definidos con precisión. La otra escuela opina que el derecho de libre determinación es el más fundamental de todos, pues cuando un pueblo o nación no puede determinar su propio destino, ningún otro derecho humano es susceptible de protección". Ibid., p. 339.
} 
tanto por el regateo como por la negación a la que han sido sometidos los derechos económicos y sociales, al responder al movimiento neoliberal que apoya decididamente al individuo como el fundamento en sentido fuerte y absoluto de cualquier sociedad. De este modo, los derechos humanos se utilizan para colapsar cualquier crítica a las diferencias entre los que tienen y no tienen condiciones para pervivir. En consecuencia, los derechos humanos al ser descritos como una serie de adquisiciones lineales y homogéneas pierden su carácter crítico, emancipatorio y disruptivo, pasando a ser objeto de "la administración" de los poderes del Estado. La indiferencia o el ocultamiento de los distintos tipos de derechos y sus proyectos políticos no le hacen un favor a sus capacidades para oponerse a cualquier tipo de tiranía y violencia.

Para América Latina que registra uno de los mayores niveles de desigualdad en el mundo, según el PNud, es prioritario que se analicen los contenidos de los derechos humanos y ocuparse del hecho de que "las dimensiones de la ciudadanía política, civil y social no estén todavía integradas. La más avanzada ha sido la primera. Todavía todas las garantías propias de la ciudadanía civil no alcanzan de manera igualitaria a todas las ciudadanas y a todos los ciudadanos." ${ }^{.33} \mathrm{Al}$ considerar la complejidad con que se ha dado el proceso de los derechos humanos en esta parte del planeta, con sus obstáculos y peculiaridades, es que se puede hablar del sentido que cobran hoy los derechos humanos. Asimismo, es de peculiar importancia reflexionar sobre la condición latinoamericana de demandas de todo tipo de derechos que no han sido consolidados por generaciones como en Europa, aquí el ritmo y el orden de aparición y desarrollo ha tenido sus propios rasgos, que son elementos que le distinguen e invitan a la elaboración de nuevas categorías y significados para los derechos humanos.

${ }^{33}$ Ideas y aportes: la democracia..., p. 26. 
EL CONCEPTO DE CIUDADANÍA NO INTEGRADA, LOS DERECHOS DE LA TERCERA GENERACIÓN (EL CASO NO CONSIDERADO POR T. H. MARSHALL)

El análisis del significado y sentido de los derechos humanos se enriquece con la discusión sobre algunos "puntos ciegos" de la teoría democrática. O’Donell señala en Ideas y aportes que la democracia política, al menos en el Noroeste, se origina y se mantiene (a pesar de la crisis por la que atraviesa) hasta nuestros días en el marco de un Estado-nación. Este hecho obvio, aunque para la democracia curiosamente omitido, tiene varias consecuencias importantes. Una es que la ciudadanía tiene dos formas:

La ciudadanía está implicada por el régimen democrático y los derechos que éste asigna a los /as ciudadanos/as, especialmente los derechos participativos de votar, ser elegido y en general tomar parte en diversas actividades políticas.

La otra cara de la ciudadanía — derivada de la nacionalidad - es un estatus adscriptivo, atribuido antes de cualquier actividad o acción voluntaria, por el hecho de pertenecer, ya sea jus solis o jus sanguinis, a la nación [... . . La ciudadanía se extendió prácticamente sobre toda la población adulta de un Estado, pero fue otorgada como un atributo de la nacionalidad por un Estado que tanto por razones domésticas como internacionales intentaba controlar a la población y a sus lealtades [...] y define la categoría de personas que los estados soberanos reconocen como objetos legítimos de sus respectivos poderes soberanos. ${ }^{34}$

Las opiniones de Tilly y O'Donell, a quienes cito a continuación, dan cuenta de los efectos de la conformación del Estado, sobre todo en su relación con los sentidos que adquiere la ciudadanía.

[... ] bajo el mapa contemporáneo de Europa yace un cementerio de estados fallidos, los que fueron derrotados y absorbidos por los estados existentes actualmente; las guerras ayudaron a producir estados altamente burocratizados, en cuyos centros existía claramente el interés de extender y legalizar su dominación sobre poblaciones que proveían los impuestos y los soldados indispensables para la sobrevivencia de dichos estados.

El Estado es un fenómeno relativamente reciente. Emergió en el Noroeste luego de largas y violentas luchas [...]. Desde sus comienzos, la democracia política

${ }^{34}$ Ibid., p. 21. 
contemporánea implica una ciudadanía de doble faz: la ciudadanía (potencialmente) activa y participativa propia de la democracia, y la segunda, adscriptiva, que resulta del hecho de pertenecer a una nación dada. ${ }^{35}$

Los ciudadanos de un Estado-nación han construido una forma de conciencia colectiva: el nosotros, que ha significado una forma de solidaridad con una historia común y una identidad que se ha delimitado en un territorio. La ciudadanía desde el contexto señalado por O'Donell y Tilly es un proceso histórico conformado por la posesión de ciertos derechos, obligaciones y deberes, adscritos a una comunidad política nacional. Es, por tanto, el ciudadano con derechos a votar y ser votado el factor básico del régimen democrático; la ampliación de esta atribución a más sectores de la población es la historia de la oposición a la inclusión: los "no merecedores" o "poco confiables" ¿cuáles eran los argumentos para esta negación? La incapacidad para la autonomía y la falta de responsabilidad en algunos individuos, lo que permite negar su agencia.

La agencia que garantiza la puesta en marcha de los derechos es un hecho institucionalizado. Es un concepto moral, filosófico, psicológico y legalmente sancionado. La presunción de agencia implicada por el régimen democrático constituye a cada individuo como una persona legal, portadora de derechos subjetivos. ${ }^{36}$

El concepto de ciudadanía definido por Marshall "como aquel estatus que se concede a los miembros de pleno derecho de una comunidad, implica que quien la posee disfruta de igualdad tanto en los derechos como en las obligaciones que impone la propia concesión". ${ }^{37}$ La ciudadanía es la suma de las posibilidades de reclamo de los derechos, esto es, las demandas por los derechos económicos y sociales integran las otras demandas de la vertiente liberal. En su planteamiento, la clase social se observa como el agente de los derechos sociales y económicos. Es la clase social la investida de capacidad para confrontar las lu-

35 "El Estado que resultó de estos procesos es un Estado absorbente, masculino y celoso". Ibid., p. 18.

${ }^{36}$ Loc. cit.

${ }^{37}$ Marshall, op. cit., p. 107. 
chas y contradicciones de un sistema capitalista, en tal lucha quedan incorporados los derechos políticos y civiles en un movimiento progresivo y comprometido con la desigualdad social.

A medida que avanzaba el siglo xx, dice Marshall, crecía la conciencia de que la política democrática necesitaba de un electorado educado, y la manufactura científica precisaba de trabajadores y técnicos formados. La obligación de mejorarse y civilizarse es, pues, un deber social, no sólo personal, porque la salud de una sociedad depende del grado de civilización de sus miembros, y una comunidad que subraya esa obligación ha empezado a comprender que su cultura es una unidad orgánica y su civilización una herencia nacional. De lo que se deduce que el aumento de la educación elemental durante el siglo xIx fue el primer paso decisivo en el camino que iba a conducir al reconocimiento de los derechos sociales de la ciudadanía en el siglo xx. ${ }^{38}$

Ahora bien, el fenómeno de los derechos humanos en América Latina es muestra de que su aparición lleva otros ritmos y otros tiempos específicos, ya que no hay un sujeto de la historia de la ciudadanía y los derechos humanos que se desenvuelva en el devenir histórico como espíritu absoluto. La conformación del Estado en América Latina viene acompañada de la imposición brutal de la pretendida cultura nacional a los grupos o comunidades con cultura propia, o bien, la asimilación que les colocó en la condición expuesta a la inequidad dentro del Estado-nación. ${ }^{39}$

La metáfora de un perfeccionamiento cronológico del tríptico de los derechos, análoga a la sucesión de las generaciones (por eso derecho de primera, segunda y tercera generación) tiene en América Latina un carácter mucho más discontinuo. Los derechos no han cobrado forma entre nosotros por acumulación sino por exclusión [... la la manipulación de los derechos políticos puso al descubierto la vigencia trunca de los derechos civiles; [... ]el impulso hacia el desarrollo de los

\footnotetext{
${ }^{38} \mathrm{Ibid} ., \mathrm{p} .35$.

${ }^{39}$ Otra forma de diferenciarlos: "La nación es una comunidad y el Estado es una asociación; la pertenencia a una nación es una cuestión de sentimientos, que dependen a su vez de la experiencia y de la historia comunes, mientras que la pertenencia a un Estado es una cuestión de status legales." D. D. Raphael, Problemas de filosofía política, Madrid, Alianza Editorial, 1983, p. 52.
} 
derechos sociales se plasmó en algunas oportunidades en detrimento de los derechos civiles y políticos y, en el límite extremo de la dictadura, conllevó su radical abolición [...] la expansión de los derechos políticos debe procurar la vigencia de los derechos civiles y sociales hondamente afectados por un contexto de insuficiencia institucional y de crecimiento de las desigualdades [...] todas estas experiencias coexisten en la historia de América Latina. ${ }^{40}$

iSe puede entonces afirmar que la etapa marshalliana está superada después de la disolución de los regímenes socialistas y el fin de la Guerra Fría? El latinoamericanista mexicano Ignacio Sosa lo advierte y dice: "En el momento en el que -algunos observadores - ponen en entredicho los derechos sociales, vale la pena preguntarse si su fundamentación ha dejado de tener valor y por qué, parece ahora que fueron producto de los regímenes nacionalistas y de los gobiernos autoritarios de distinto tipo, pero que nunca tuvieron razón de ser." ${ }^{\prime 11}$ Los hechos arrojan la evidencia de que sobre viejas desigualdades se alzan otras pertenecientes a las nuevas poblaciones marginadas, con demandas de carácter económico, teórico, polííico, jurídico, etc. Entre los grandes retos que se le presentan a los derechos humanos y a la ciudadanía se cuenta el problema de redefinir la justicia social, porque los reclamos de las diferencias étnicas y culturales no se resuelven en el entendimiento de la ciudadanía como hasta hoy se le ha definido, puesto que los derechos de identidad y la diferencia suponen condiciones cualitativas, que no se cumplen con apelar al individuo autónomo dueño de sí mismo y de sus propiedades. Es decir, la idea de ciudadanía no agota la apelación a los derechos humanos.

El gran reto de este siglo xxi es configurar un orden mundial, en el que los derechos humanos constituyan realmente la base del derecho y la política, en ese tenor y búsqueda es que se escuchan opiniones como la que nos proporciona T. Bottomore cuando dice:

${ }^{40}$ La democracia en América Latina..., Parte I, p. 33.

${ }^{41}$ Ignacio Sosa, "Garantías individuales y derechos sociales: una polémica que no termina", en Abelardo Villegas et al., Democracia y Derechos Humanos, México, Miguel Ángel Porrúa/Coor dinación de Humanidades, 1994, p. 57. 
La alternativa estaría en concebir un cuerpo de derechos humanos para cada individuo en la comunidad donde vive o trabaja, con independencia de sus orígenes nacionales y su ciudadanía formal. El cuerpo de derechos variará necesariamente entre los distintos grupos de países, y dependerá en gran medida, sobre todo en el caso de los derechos sociales, del nivel del desarrollo económico y social [ . . . ].Y que debemos examinar los derechos civiles, políticos y sociales no tanto en el marco de la ciudadanía como en el de una concepción general de los derechos humanos. ${ }^{42}$

Tal planteamiento se dirige a promover la idea de que los derechos humanos son el eje de las relaciones políticas y culturales, mas no de la ciudadanía. Se puede entender también como una invitación a transponer la ciudadanía como la fuente de adscripción de derechos a favor de una nueva formulación, es decir, se apunta a una redistribución de derechos que no sea ciega de las diversas extracciones culturales. Propuesta estimulante para la reflexión sobre la condición ético-política de los derechos humanos y la ciudadanía en estas regiones de América Latina, con una trayectoria histórica peculiar, en la que el individuo como agente o sujeto de derechos no ha tenido nunca un esplendor como en el Noroeste, la cual requiere de formulaciones nuevas para la protección de todas las generaciones de derechos humanos, y de todos los humanos ya sean ciudadanos o no lo sean.

La igualdad que implica el concepto de ciudadanía se opone a cualquier diferencia jerárquica entre los individuos como sucede en sociedades corporativas,

la mentalidad que inspiró los esfuerzos por eliminar las barreras surgió de una concepción de la igualdad que superaba las limitaciones, la concepción de un valor social igual, no sólo de derechos naturales iguales. Así aunque la ciudadanía, incluso a finales del siglo xIx, había hecho poco por reducir la desigualdad social, sí lo hizo por guiar el progreso a través de la senda que conducía hacia las políticas igualitarias del siglo $\mathrm{xx}^{43}$

${ }^{42}$ Marshall, op. cit., pp. 110 y 136.

${ }^{43}$ Ibid., p. 46. 
Es importante señalar que la ciudadanía ha aportado la posibilidad de igualar a los humanos y superar las jerarquías entre los individuos y grupos, que impedían que la ley fuese aplicada del mismo modo para todos. Este fenómeno de la superación de las desigualdades trajo consigo la participación democrática. Sin embargo, existen otros ejes de desigualdad que no pueden ser abordados desde este tipo de igualación, pues no quieren desaparecerla como sí es el caso de la clase social, sino que desean una desigualdad en la igualdad, lo que implica que la ciudadanía y los derechos humanos deben tener apertura a otras formas de pensar las prácticas de participación y de protección de los derechos humanos. Finalmente hay que recuperar al destinatario de los derechos humanos, las personas y no únicamente los ciudadanos.

\section{CONCLUSIONES}

Los planteamientos aquí expuestos han fijado el objetivo de proponer algunos contornos resultantes del análisis de los conceptos de ciudadanía y derechos humanos. Uno de los aspectos que cabe destacar es que si la ciudadanía se refiere a un cuerpo homogéneo de miembros iguales, sin jerarquías que los discriminen, entonces la argumentación sobre esta díada asume que la ciudadanía y los derechos humanos son compatibles, y no se problematiza que los derechos humanos excluyan a quienes no tengan esa categoría. Pero, si se atiende la incapacidad de la ciudadanía nacional para incorporar a todos aquellos humanos que no son parte de la llamada mayoría, aparecen cuestiones de otra índole, que exigen reflexionar sobre esa exclusión, ya que la organización de la sociedad basada en los derechos o las reivindicaciones que se deriven de la pertenencia grupal es diametralmente opuesta al concepto de ciudadanía, como lo señaló Marshall, si se da prioridad a la diferenciación de grupo, no podrá haber un estatus común. ${ }^{44}$ Aspectos muy relevantes para las implicaciones políticas, ya que las reclamaciones de derechos a la diversidad cultural no tienen por qué signi-

${ }^{44}$ Véase Giovanna Procacci, "Ciudadanos pobres, la ciudadanía social y la crisis de los estados del bienestar", en García y Lukes, op. cit., p. 23. 
ficar permanecer a la saga de la participación política, puesto que el no reconocimiento a esos derechos va de la mano de su descalificación para participar en la vida pública.

Por esto mismo, se dice que los derechos de las culturas y minorías étnicas no son ni equivalentes ni una mera sucesión progresiva de los derechos sociales y económicos, como éstos tampoco lo son de los civiles y políticos, lo que constituye otro indicio de la necesaria solicitud de nuevos enfoques para comprender las relaciones entre derechos humanos y ciudadanía. Si ella, la ciudadanía, acapara el proceso de los derechos humanos, éstos quedarán sofocados en un saco que les limita su interconexión y expansión. Sin embargo, si no hay un lugar común en el que los ciudadanos discutan, no hay polis, es decir, no hay actividad política posible. Esta oposición de los términos, o derechos individuales universales o derechos culturales locales exige una atención específica.

Desde estas afirmaciones, se hace necesario hacer un recuento de propuestas y posturas, sobre todo ante la idea de que los derechos a la diferencia e identidad no se resuelven en la ciudadanía enlazada a la noción de clase social y/o de sujeto ciudadano. Por ejemplo, si se afirma que el concepto de ciudadanía no comulga con la idea acerca de que la asignación de derechos esté sujeta a la de pertenencia a cierto grupo cultural, luego, el concepto de ciudadanía no puede ser abordado desde las jerarquías entre los miembros de una nación, porque nació en la modernidad para oponerse a las desigualdades entre los individuos ante la ley del antiguo régimen.

Preocupa en especial, que si se da prioridad a la diferenciación de grupo no podrá haber un estatus común, porque si no hay un lugar común cómo se va a participar políticamente. Además, también surgen otras inquietudes, como las que se advierten al plantear que "los derechos colectivos terminen en tiranía en ausencia de los derechos individuales" ${ }^{45}$ Lo que da entrada a cuestiones tales como: icuáles son los criterios de los grupos o culturas para identificar al interior

${ }^{45}$ Véase Michael Ignatieff, Los derechos humanos como política e idolatría, Barcelona, Paidós, 2003, pp. 20 y 169. 
a los desfavorecidos? ¿Cómo se procede a calificar la propia jerarquía de valores? ¿Quién define los derechos dentro del grupo? ${ }^{246}$

Pero estas interrogantes son simultáneas de aquéllas que apuntan a que si el individuo ciudadano es percibido como el elemento sin el cual no se puede hablar de ciudadanía, por ende se contribuye a justificar la discriminación de todos los que no tengan agencia como ciudadano, y de paso también se le excluye por tener o pertenecer a una cultura diferente, pues no es un miembro que se le parezca al individuo de la propiedad privada, que es el sujeto racional y autónomo.

La perspectiva de los derechos a la diferencia e identidad culturales tiene la peculiaridad de que

la mayoría de los derechos de reconocimiento que se plantean dentro de la llamada "política de la identidad" son en realidad redistributivos. Por una parte, son reclamaciones de reconocimiento simbólico, y esto entraña en general la asignación de recursos y/o derechos. Por otra, las reclamaciones basadas en identidades colectivas son, en algunas sociedades contemporáneas, más efectivas que las de clase, en la movilización de apoyo y a veces para conseguir la aquiescencia de otros sectores de la población. ${ }^{47}$

La Caída del Muro de Berlín, la desaparición de la Unión Soviética y el fenómeno de la economía globalizada han sido sucesos que acompañan el fenómeno del debilitamiento del Estado como el gran rector de la economía nacional. Situación que tiene implicaciones de gran alcance en todos los asuntos que hasta el momento hemos mencionado, por ejemplo, se observa que el Estado se está retirando de algunas de las responsabilidades que lo definían como garante de la defensa de los intereses generales y, en particular, de los intereses de los más débiles.

\footnotetext{
${ }^{46} \mathrm{La}$ forma en que se han resuelto algunos de estos cuestionamientos en ciertos países como en Canadá y Australia pone de relieve la discusión acerca de si salvar la dignidad de los ciudadanos, tanto en un ámbito colectivo como en el individual, conlleva la aceptación por parte de los grupos minoritarios de las normas aceptadas por la mayoría para la protección de la dignidad humana individual. Que para el caso de México y Latinoamérica ofrece un antecedente digno de revisión para sopesar sus alcances y limitaciones.

${ }^{47}$ García y Lukes, op. cit., p. 3.
} 
Por ello, es comprensible lo que Boaventura de Sousa señala: "la crisis del Estado regulador y del Estado protector y la situación de crisis de emancipación social -simbolizada por la crisis de la revolución social radical y del socialismo en tanto paradigma de la transformación social radical — ha dejado de ser una tensión creativa. La emancipación dejó de ser la contraparte de la regulación para volverse el doble de la misma". ${ }^{48}$

En los intentos de avance teórico sobre estas preocupaciones es pertinente no dejar de lado la paradójica situación que rodea tanto la defensa de los derechos humanos incluyente de las demandas de dimensión civil, políica, económica, social, cultural y grupal, como la de quienes los acotan exclusivamente a las de un sujeto con necesidades específicas que se generalizan y pasan por ser universales. El Estado en las condiciones actuales experimenta una pérdida de soberanía, al tiempo que no existen un Estado global y una ciudadanía global. Y, por otro lado, se "está proclamando la democracia en el momento mismo en que los cambios en el orden internacional están comprometiendo la posibilidad de una nación-Estado democrática independiente.”蜪 ¿En qué estamos?

Si la política es el arte de gobernar el espacio público que se comparte, con ideas plurales, identidades diversas e intereses contrapuestos, es imprescindible comprender que este espacio se proyecta en lo local y en lo global. Vale decir en lo intranacional y en lo supranacional. [...] Estamos viviendo en cuatro espacios públicos relevantes: el local interno, el del Estado nacional clásico, el regional supranacional y el global. Pero la política se realiza en los dos primeros - en el mejor de los casos-, mientras los siguientes, cada vez más decisivos para la vida de los ciudadanos, escapan del control de los representantes..$^{50}$

\footnotetext{
${ }^{48}$ Boaventura de Sousa, Por una concepción multicultural de los derechos humanos, México, Centro de Investigaciones Interdisciplinarias en Ciencias y Humanidades-unam, 1998, p. 11.

${ }^{49}$ David Held, op. cit., p. 361. Otra obra en la que aborda con agudeza estos asuntos es La democracia en el orden global. Del Estado moderno al gobierno cosmopolita, Barcelona, Paidós, 1997.

${ }^{50}$ Palabras de Felipe González, "Crisis de la política: causas y respuestas eficientes", en La democracia en América Latina..., p. 49.
} 
El clima que se experimenta en América Latina, Europa y el resto del mundo es interpretado certeramente por Lechner, diagnostica que en el entorno hay desvanecimiento de los afectos, "se propicia la conducta cool, irónica, light". Ahora, el papel del Estado democrático no es requerido pues para qué ser democráticos si cualquier ejercicio de discernimiento es fugaz y no tiene dirección definida.

Las grandes transformaciones en curso - desde el colapso del comunismo hasta la globalización del mercado- están conformando un nuevo contexto de la acción política. Pero cambia no solamente el contexto de la acción política, sino la política misma. Los mitos y símbolos, las imágenes y liturgias que movilizaban y cohesionaban las creencias de los gobernados y gobernantes en torno a ciertos principios básicos como soberanía popular, representación política, deliberación ciudadana, opinión pública, pierden eficacia y dejan al desnudo el "juego democrático". En este sentido, vivimos una época de desencanto; desencantamiento que no se refiere tanto a la frustración de determinadas expectativas acerca del funcionamiento del régimen democrático como el desmoronamiento de las representaciones simbólicas que sustentaban la democracia. Su densidad simbólica se debilita y, por ende, las democracias latinoamericanas no logran encarnar una comunidad que cristalice las necesidades de pertenencia y arraigo social. ${ }^{51}$

La búsqueda de nuevas interpretaciones de los derechos humanos requiere de las posibilidades que cobren sentido, es decir, significa proponer condiciones de existencia para diversos caminos. Dicho con otras palabras, sólo si los derechos humanos provocan y suscitan compromisos con su defensa, entonces, surge su posibilidad de ser. En este momento, sin perseguir respuestas de carácter ontológico para la capacidad humana de interrogarse por el sentido, es benéfico bregar sobre el sentido de los derechos humanos para los ciudadanos, para los gobernantes, para las personas que habitamos el mundo. Por lo tanto, no significará lo mismo la defensa de unos derechos humanos que olviden al individuo, o bien, que exterminen la dimensión individual a favor del grupo. No significa lo mismo vivir en condiciones donde se puedan reclamar los excesos del Estado que no hacerlo, no son lo mismo la democracia que la dictadura.

${ }^{51}$ Norbert Lechner, Las sombras del mañana, Chile, Lom Ediciones, 2002, pp. 24 y 26. 
En América Latina, en 200 años de vida independiente la democracia nació y murió decenas de veces. Mientras se la consagraba en las constituciones, se la destruía en la práctica. Guerras, tiranías y breves primaveras componen gran parte de esta historia independiente, durante la cual hasta flagrantes violaciones a la democracia fueron hechas en su nombre. Hacia 1978 se abrió una época sin precedentes en la región. Poco a poco, los regímenes autoritarios dieron paso a regímenes democráticos. Nunca antes ha habido tantos países con regímenes democráticos y nunca antes han sido tan durables las democracias latinoamericanas. Pero lo conquistado no está asegurado [... ] en América Latina la democracia política convive con un Estado de derecho limitado y con serios problemas económicos y sociales. En 2003 la pobreza alcanzó 43\% y la pobreza extrema 19.4\% de la población. Además, la región registra uno de los mayores niveles de desigualdad en el mundo. ${ }^{52}$

En "Latinoamérica que es múltiple, y es una", la rehabilitación de la política en vinculación con el fortalecimiento de la democracia son las condiciones para hablar del sentido ético-político de los derechos humanos. Lo que implica bregar en la configuración de formas de gobierno y autoridad comprometidos con la capacidad de dotar a la ciudadanía de nuevos derroteros, se requieren pues, nuevos paradigmas de interpretación y de acción. Decir esto no es cuestión de remitirme al trabajo de los políticos, sino más allá, es una convocatoria para los intelectuales y para la población. Reflexionar los derechos humanos asumiendo la globalización del mercado y la cultura posmoderna ${ }^{53}$ tiene tareas pendientes, como la de proponer modelos políticos que ya no estén desarticulados de los entornos efectivos y diversos, sino de su reconocimiento y del fomento al diálogo entre ellos. Los derechos humanos son posibilidades a favor de la humanidad en diversos contextos, en los que el poder político exceda sus funciones, o cuando transgreda la dignidad y la autenticidad de los que no son legales den-

${ }^{52}$ Ideas y aportes: la democracia en América Latina ..., p. 25.

53 "Si ser moderno significa encontrarnos en un ambiente que nos promete aventura, poder, alegría, crecimiento, transformación de nosotros mismos y del mundo, que al mismo tiempo amenaza con destruir todo lo que tenemos, todo lo que conocemos, todo lo que somos" cabría decir que el clima posmoderno al que hemos ingresado, en cambio, sólo nos deja con la segunda parte de esta ecuación." José Joaquín Brunner, Globalización cultural y posmodernidad, Santiago de Chile, FCE, 1999, p. 47. 
tro de sus fronteras. La defensa de los nacionales nunca debe estar por encima de la defensa de la humanidad de cualquier persona, el carácter de ciudadanía no tiene por qué negar a los no ciudadanos derechos sociales a la salud, etc., ni sus derechos a ser culturalmente diversos. Si este principio ético no sustenta a todo proyecto político, los derechos humanos serán empleados para justificar violencia, discriminación, vejación y opresión de unos humanos sobre otros, simplemente carecerán de sentido.

Recibido: 21 de mayo, 2010.

Aceptado: 22 de junio, 2010. 